\title{
Small for Gestational Age and Magnesium in Cord Blood Platelets: Intrauterine Magnesium Deficiency May Induce Metabolic Syndrome in Later Life
}

\author{
Junji Takaya and Kazunari Kaneko \\ Department of Pediatrics, Kansai Medical University, 10-15 Fumizonocho, Moriguchi, Osaka 570-8506, Japan \\ Correspondence should be addressed to Junji Takaya, takaya@takii.kmu.ac.jp \\ Received 6 October 2010; Accepted 30 November 2010 \\ Academic Editor: R. L. Deter
}

Copyright (C) 2011 J. Takaya and K. Kaneko. This is an open access article distributed under the Creative Commons Attribution License, which permits unrestricted use, distribution, and reproduction in any medium, provided the original work is properly cited.

Magnesium deficiency in pregnancy frequently occurs because of inadequate or low intake of magnesium. Magnesium deficiency during pregnancy can induce not only maternal and fetal nutritional problems, but also consequences that might last in offspring throughout life. Many epidemiological studies have disclosed that small for gestational age (SGA) is associated with an increased risk of insulin resistance in adult life. We reported that intracellular magnesium of cord blood platelets is lower in SGA groups than that in appropriate for gestational age groups, suggesting that intrauterine magnesium deficiency may result in SGA. Taken together, intrauterine magnesium deficiency in the fetus may lead to or at least program insulin resistance after birth. In this review, we propose that intrauterine magnesium deficiency may induce metabolic syndrome in later life. We discuss the potential contribution of aberrant magnesium regulation to SGA and to the pathogenesis of metabolic syndrome.

\section{Introduction}

Magnesium $(\mathrm{Mg})$ is an important cofactor for the enzymes that are involved in carbohydrate metabolism: an important role of $\mathrm{Mg}$ in insulin action has been reported [1,2]; low serum and intracellular $\mathrm{Mg}\left(\left[\mathrm{Mg}^{2+}\right]_{i}\right)$ concentrations are associated with insulin resistance, impaired glucose tolerance, and decreased insulin secretion [3,4]. Furthermore, lower dietary $\mathrm{Mg}$ intake could cause insulin resistance both in children and adults $[5,6]$. Based on these findings, we studied whether low $\left[\mathrm{Mg}^{2+}\right]_{i}$ in the fetus would be one of the critical abnormalities associated with small for gestational age (SGA).

In addition, several studies have shown the association of size at birth or indices in poor fetal growth with later development of metabolic syndrome and insulin resistance [7]. Hales et al. proposed that impaired glucose tolerance and type 2 diabetes might arise as a result of programming [8]. Programming is a term used to describe persistent changes in organ structure and function caused by exposure to adverse environmental influences during critical periods of development [9]. These findings have led to the "fetal origin" hypothesis, which proposes that fetal adaptation to an adverse intrauterine environment affecting fetal growth may program life-long physiological changes [10]. It has been proposed that various fetal growth patterns and intrauterine growth retardation (IUGR) arise as a result of an early stimulus or insult. Since both fetal weight and length gains are closely related, there is much overlap between SGA and IUGR. We focus on intrauterine undernutrition and SGA. SGA is defined as birth weight and/or length at least 2 standard deviations below the mean for gestational age.

In this review, we discuss the potential contribution of aberrant $\mathrm{Mg}$ regulation to SGA and to the pathogenesis of metabolic syndrome later in life.

\section{Magnesium Deficiency During Pregnancy}

It is reported that the amount of maternal $\mathrm{Mg}$ intake is not only associated with pregnancy outcome but also with infant outcome [11]. The mean daily intake of $\mathrm{Mg}$ (284.3 mg/day) 
during pregnancy was found to be lower than recommended [12]. For example, $\mathrm{Mg}$ deficiency is reported to occur in $44 \%$ of pregnant Indian women [13]. Another study has demonstrated that mothers who drink water containing high amounts of $\mathrm{Mg}$ have a reduced risk of having very low birth weight infants (less than 1,500 g of birth weight) [14]. By the end of a normal pregnancy, the fetus is believed to have acquired approximately $28 \mathrm{~g}$ of calcium, $16 \mathrm{~g}$ of phosphorous, and $0.7 \mathrm{~g}$ of $\mathrm{Mg}$, mostly during the third trimester, also the time when $80 \%$ of fetal accretion of $\mathrm{Mg}$ occurs [15].

The fetal circulation contains higher levels of total calcium, ionized calcium, and $\mathrm{Mg}$ compared to maternal blood [16]. In the placental membrane, copper and selenium share the same transport pathway along a concentration gradient in the maternal-fetal direction, while $\mathrm{Mg}$ and iron use predominantly an active transport pathway [17]. In fact, evidence for an active transport mechanism for $\mathrm{Mg}$ in the placenta has been demonstrated in cultured trophoblast cells in which low $\left[\mathrm{Mg}^{2+}\right]_{i}$ is maintained by the function of a $\mathrm{Na}^{+} / \mathrm{Mg}^{2+}$ exchanger [18]. Mg levels in umbilical cord blood are the lowest in preterm low birth weight babies, followed by term low birth weight babies and are the highest in term controls $(P<.05)[19]$.

Calcium and $\mathrm{Mg}$ have an immediate effect on placental vascular flow. Reduced placental vascular flow is at least, in part, responsible for placental insufficiency and fetal growth retardation (FGR). Calcium and $\mathrm{Mg}$ are cofactors of a variety of enzymes. A variety of hormones, cytokines, and growth factors produced by fetal membranes and the placenta can act locally on the myometrium [20]. The ability of the uterine artery to dilate during pregnancy may be specifically related to the upregulation of multiple pathways for the production of nitric oxide [21]. The activity of constitutive nitric oxide synthase is dependent on calcium and is inhibited by a reduction in the concentration of $\mathrm{Mg}$ [22].

Blood Mg levels were reportedly lower in women with severe pre-eclampsia than in healthy pregnant women $(1.63 \pm 0.05 \mathrm{mg} / \mathrm{dL}$ versus $1.87 \pm 0.05 \mathrm{mg} / \mathrm{dL} ; P<.001)$ [23]. $\mathrm{Mg}$ is widely used in obstetric practice to treat preeclampsia. Therapeutic levels of $\mathrm{Mg}$ have also been found to produce specific placental effects such as vasodilation [24]. From an in vitro study of human umbilical artery resistance [25], Mg sulfate was found to exert a relaxant effect on umbilical arterial tone attenuating the vasoconstrictor effect of angiotensin II and endothelin-1 in the fetal-placental vasculature. $\mathrm{Mg}$ sulfate used for the treatment of pre-eclampsia or hypertensive disease in pregnancy may have beneficial effects on the fetoplacental circulation. Prenatal treatment with Mg sulfate may influence calcium homeostasis and nonenzymatic antioxidant reserve in erythrocytes of preterm newborns [26].

\section{Mg Supplements and Pregnancy Outcome}

It is well known that plasma Mg falls in pregnancy because of accumulation of ion in the placenta and fetus. $\mathrm{Mg}$ is therefore widely given as a supplement during pregnancy, particularly in cases of preterm labor. There are several reports that oral $\mathrm{Mg}$ supplementation in pregnancy is safe and that it has a positive effect on fetal morbidity [27]. Patients in preterm labor have significantly depressed serum Mg levels, while in patients with pre-eclampsia, $\mathrm{Mg}$ levels are not significantly different from that of the controls [28]. Mg supplementation was found to decrease the rate of FGR, premature rupture of membranes, and premature delivery in risk pregnancies treated with betamimetics [29]. Oral Mg supplementation given before the 25th week of gestation is associated with a lower frequency of preterm births, a lower frequency of low birth weight, and fewer SGA infants compared with the placebo [30]. Mg intake in 513 women who were near the end of their first trimester of pregnancy was determined from records of food consumption. $\mathrm{Mg}$ intake correlated with weight, length, and head circumference at birth as well as length of gestation up to a threshold of around 3,200 g of birth weight [31]. On the other hand, $\mathrm{Mg}$ supplements ( $100 \mathrm{mg} /$ day) taken during the second and third trimesters had no effect on the outcome of the pregnancy. The effect of $\mathrm{Mg}$ compared with placebo in a randomized doubleblind controlled study of patients with pregnancy-induced hypertension was investigated [32]. Mg supplementation was found to be beneficial in the management of pregnancyinduced hypertension.

At present, there is insufficient high-quality evidence to show that dietary $\mathrm{Mg}$ supplementation during pregnancy is beneficial [30]. Any influence of $\mathrm{Mg}$ has been confined to the first trimester or earlier. It is important to determine the timing and dose of $\mathrm{Mg}$ supplementation as both factors may alter the pregnancy outcome.

\section{The Relation of SGA to Intracellular Magnesium in Cord Blood Platelets}

We have previously reported that intracellular magnesium $\left(\left[\mathrm{Mg}^{2+}\right]_{i}\right)$ is lower in children with diabetes mellitus and in children who are obese [33]. In the type 2 diabetes mellitus and obese groups, platelets responded well to insulin. Under insulin-resistant states, $\left[\mathrm{Mg}^{2+}\right]_{i}$ decreases before the poor reactivity to insulin occurs in platelets. From these findings, we hypothesize that $\left[\mathrm{Mg}^{2+}\right]_{i}$ is decreased earlier than when poor reactivity to insulin develops in platelets exposed to an insulin resistant environment. This suggests that low $\left[\mathrm{Mg}^{2+}\right]_{i}$ may be an intrinsic abnormality in infants with low birth weight [33]. To test this hypothesis, we studied the relationship of $\left[\mathrm{Mg}^{2+}\right]_{i}$ in cord blood platelets to birth weight [34]. We found that mean basal $\left[\mathrm{Mg}^{2+}\right]_{i}$, but not plasma magnesium, is lower in SGA than in the appropriate for gestational age (AGA) groups $(323 \pm 162 \mu \mathrm{mol} / \mathrm{L}$ versus $488 \pm 132 \mu \mathrm{mol} / \mathrm{L}, P=.004)$. Basal $\left[\mathrm{Mg}^{2+}\right]_{i}$ significantly correlates with birth weight $(P<.0001)$ as well as cord plasma leptin $(P=.031)$ and IGF-1 $(P<.001)$ [35]. $\left[\mathrm{Mg}^{2+}\right]_{i}$ as well as leptin and IGF-1 reflects the extent of fetal growth. Also, $\left[\mathrm{Mg}^{2+}\right]_{i}$ significantly correlates with the quantitative insulin sensitivity check index (QUICKI)) $(P<$ $.001)$. Decreased $\left[\mathrm{Mg}^{2+}\right]_{i}$ in SGA might underlie the initial pathophysiological events that lead to insulin resistance. 
Several factors are reported to affect $\left[\mathrm{Mg}^{2+}\right]_{i}$. For example, hyperglycemia may have an effect on $\mathrm{Mg}^{2+}$ transport and induce a decline of $\left[\mathrm{Mg}^{2+}\right]_{i}$. Barbagallo et al. reported that responses to hyperglycemia in vitro were blunted in adult hypertensive subjects and that these responses were closely linked to basal $\left[\mathrm{Mg}^{2+}\right]_{i}$ levels [36]. In our study, we found no correlation between cord plasma glucose and basal $\left[\mathrm{Mg}^{2+}\right]_{i}$ levels. In addition, we did not find any significant difference in plasma glucose levels between the SGA and AGA groups. Intrauterine glucose levels may have less of an effect on inducing SGA or low $\left[\mathrm{Mg}^{2+}\right]_{i}$. As $\left[\mathrm{Mg}^{2+}\right]_{i}$ plays a promotive role in fetal growth, low $\left[\mathrm{Mg}^{2+}\right]_{i}$ may partly be responsible for SGA.

As low $\left[\mathrm{Mg}^{2+}\right]_{i}$ is an intrinsic abnormality seen in infants with low birth weight, it is considered that fetal $\mathrm{Mg}$ deficiency is an important determinant of insulin resistance in later life [33]. In fact, our data was supported by a recent animal study demonstrating that maternal $\mathrm{Mg}$ restriction irreversibly increases body fat and induces insulin resistance in pups by 6 months of age [37].

\section{Fetal Programming}

The fetal origin hypothesis by Barker et al. [8-10] states that fetal undernutrition in middle to late gestation leads to disproportionate fetal growth programs and later metabolic diseases. Fetal programming is a phenomenon in which alterations in fetal growth and development in response to the prenatal environment have long-term or permanent effects. This theory was further established in the category of developmental origins of health and disease (DOHaD) [38]. The mechanisms thought to be responsible for fetal programming include the direct effects on cell number, altered stem cell function, and the resetting of regulatory hormonal axes: hypothalamic-pituitary-adrenal axis $[39,40]$ and growth hormone insulin-like growth factor axis [41]. One of the underlying mechanisms for the postulated early-life programming is that of epigenetics. Altered epigenetic regulation of genes in phenotype induction could possibly give rise to interventions that modify long-term disease risk associated with unbalanced nutrition in early life [42]. Venu et al. reported that fasting insulin and Homeostasis Model Assessment-Insulin Resistance (HOMA-IR) increased in offspring from Mg-restricted dams at 6 months of age [37]. Maternal and postnatal $\mathrm{Mg}$ status is important in the long-term programming of body adiposity and insulin secretion in rat offspring [43].

Although low birth weight and poor prenatal nutrition are strongly associated with metabolic syndrome in later life, postnatal catch-up growth was recently considered to also be a pivotal element associated with the development of various pathological conditions [44]. The concept of a sensitive or crucial period that operates to cause long-term changes in development and adverse outcomes later in life is an intriguing one and should be the focus of more studies in the future.

\section{Conclusion}

Birth weight is only a crude index of early growth and indicates nothing about the success of a fetus in achieving its growth potential. $\left[\mathrm{Mg}^{2+}\right]_{i}$ may be a marker of early growth restriction, which may be of future diagnostic use as an early predictor of adult diseases. Low $\left[\mathrm{Mg}^{2+}\right]_{i}$, which may represent the prenatal programming of insulin resistance, has lifelong effects on metabolic regulation. A biological interpretation of the association between birth size and risk of insulin-resistant diseases should emphasize the possible underlying roles of $\left[\mathrm{Mg}^{2+}\right]_{i}$.

\section{Abbreviations}

AGA: Appropriate for gestational age

FGR: Fatal growth retardation

Mg: $\quad$ Magnesium

$\left[\mathrm{Mg}^{2+}\right]_{\mathrm{i}}$ : Intracellular magnesium

SGA: Small for gestational age.

\section{Acknowledgments}

Part of this study was supported by the Mami Mizutani foundation and by a Grant-in-Aid for Scientific research (C) from the Japanese Society for the Promotion of Science (no. 21591424). The authors would like to thank the Danone Institute of Japan for its financial support of the 2009 DIJ Research Grant.

\section{References}

[1] G. Paolisso, A. Scheen, F. D. D'Onofrio, and P. Lefebvre, "Magnesium and glucose homeostasis," Diabetologia, vol. 33, no. 9, pp. 511-514, 1990.

[2] H. Rosolová, O. Mayer Jr., and G. M. Reaven, "Insulinmediated glucose disposal is decreased in normal subjects with relatively low plasma magnesium concentrations," Metabolism, vol. 49, no. 3, pp. 418-420, 2000.

[3] J. Takaya, H. Higashino, and Y. Kobayashi, "Intracellular magnesium and insulin resistance," Magnesium Research, vol. 17, no. 2, pp. 126-136, 2004.

[4] L. M. Resnick, R. K. Gupta, H. Gruenspan, and M. H. J. H. Alderman Laragh, "Hypertension and peripheral insulin resistance. Possible mediating role of intracellular free magnesium," American Journal of Hypertension, vol. 3, no. 5, part 1, pp. 373-379, 1990.

[5] M. G. Huerta, J. N. Roemmich, M. L. Kington et al., "Magnesium deficiency is associated with insulin resistance in obese children," Diabetes Care, vol. 28, no. 5, pp. 1175-1181, 2005.

[6] J. L. Nadler, T. Buchanan, R. Natarajan, I. Antonipillai, R. Bergman, and R. Rude, "Magnesium deficiency produces insulin resistance and increased thromboxane synthesis," Hypertension, vol. 21, no. 6, pp. 1024-1029, 1993.

[7] D. J. P. Barker, C. N. Hales, C. H. D. Fall, C. Osmond, K. Phipps, and P. M. S. Clark, “Type 2 (non-insulin-dependent) diabetes mellitus, hypertension and hyperlipidaemia (syndrome X): relation to reduced fetal growth," Diabetologia, vol. 36, no. 1, pp. 62-67, 1993. 
[8] C. N. Hales and D. J. P. Barker, "The thrifty phenotype hypothesis," British Medical Bulletin, vol. 60, pp. 5-20, 2001.

[9] A. Lucas, "Programming by early nutrition: an experimental approach," Journal of Nutrition, vol. 128, no. 2, supplement, pp. 401S-406S, 1998.

[10] C. Kanaka-Gantenbein, "Fetal origins of adult diabetes," Annals of the New York Academy of Sciences, vol. 1205, pp. 99$105,2010$.

[11] N. O. E. Barbosa, T. S. Okay, and C. R. Leone, "Magnesium and intrauterine growth restriction," Journal of the American College of Nutrition, vol. 24, no. 1, pp. 10-15, 2005.

[12] W. Denguezli, R. Faleh, A. Hajjaji et al., "Maternal nutrition as a determinant of fetal weight: role of trace elements and vitamins," Journal de Gynecologie Obstetrique et Biologie de la Reproduction, vol. 36, no. 5, pp. 473-478, 2007.

[13] P. Pathak, S. K. Kapoor, U. Kapil, and S. N. Dwivedi, "Serum magnesium level among pregnant women in a rural community of Haryana State, India," European Journal of Clinical Nutrition, vol. 57, no. 11, pp. 1504-1506, 2003.

[14] C. Y. Yang, H. F. Chiu, S. S. Tsai, C. C. Chang, and F. C. Sung, "Magnesium in drinking water and the risk of delivering a child of very low birth weight," Magnesium Research, vol. 15, no. 3-4, pp. 207-213, 2002.

[15] E. M. Widdowson, "Changes in body composition during growth," in Scientific Foundations of Paediatrics, J. A. Davis and J. Dobbing, Eds., pp. 330-342, William Heinemann, London, UK, 1981.

[16] S. M. Husain and M. Z. Mughal, "Mineral transport across the placenta," Archives of Disease in Childhood, vol. 67, no. 7, pp. 874-878, 1992.

[17] M. Nandakumaran, H. M. Dashti, and F. Surname, "Maternalfetal transport kinetics of copper, selenium, magnesium and iron in perfused human placental lobule: in vitro study," Molecular and Cellular Biochemistry, vol. 231, no. 1-2, pp. 914, 2002.

[18] P. R. Standley and C. A. Standley, "Identification of a functional $\mathrm{Na} / \mathrm{Mg}$ exchanger in human trophoblast cells," American Journal of Hypertension, vol. 15, no. 6, pp. 565-570, 2002.

[19] K. E. Elizabeth, V. Krishnan, and T. Vijayakumar, "Umbilical cord blood nutrients in low birth weight babies in relation to birth weigjt \&amp; gestational age," Indian Journal of Medical Research, vol. 128, no. 2, pp. 128-133, 2008.

[20] P. Bischof, A. Meisser, and A. Campana, "Paracrine and autocrine regulators of trophoblast invasion-a review," Placenta, vol. 21, supplement A, pp. S55-S60, 2000.

[21] FU. X. Yi, R. R. Magness, and I. M. Bird, "Simultaneous imaging of $\left[\mathrm{Ca}^{2+}\right]_{1}$ and intracellular NO production in freshly isolated uterine artery endothelial cells: effects of ovarian cycle and pregnancy," American Journal of Physiology, vol. 288, no. 1, pp. R140-R148, 2005.

[22] P. J. Pearson, P. R. B. Evora, J. F. Seccombe, and H. V. Schaff, "Hypomagnesemia inhibits nitric oxide release from coronary endothelium: protective role of magnesium infusion after cardiac operations," Annals of Thoracic Surgery, vol. 65, no. 4, pp. 967-972, 1998.

[23] M. Gulaboglu, B. Borekci, and Z. Halici, "Placental tissue iodine level and blood magnesium concentration in preeclamptic and normal pregnancy," International Journal of Gynecology and Obstetrics, vol. 98, no. 2, pp. 100-104, 2007.
[24] R. David, I. M. Leitch, M. A. Read, A. L. A. Boura, and W. A. W. Walters, "Actions of magnesium, nifedipine and clonidine on the fetal vasculature of the human placenta," Australian and New Zealand Journal of Obstetrics and Gynaecology, vol. 36, no. 3, pp. 267-271, 1996.

[25] G. Holcberg, O. Sapir, M. Hallak et al., "Selective vasodilator effect of magnesium sulfate in human placenta," American Journal of Reproductive Immunology, vol. 51, no. 3, pp. 192197, 2004.

[26] L. Zylinska, E. Gulczynska, and A. Kozaczuk, "Changes in erythrocyte glutathione and plasma membrane calcium pump in preterm newborns treated antenatally with MgSO4," Neonatology, vol. 94, no. 4, pp. 272-278, 2008.

[27] L. Spatling and G. Spatling, "Magnesium supplementation in pregnancy. A double-blind study," British Journal of Obstetrics and Gynaecology, vol. 95, no. 2, pp. 120-125, 1988.

[28] R. B. Kurzel, "Serum magnesium levels in pregnancy and preterm labor," American Journal of Perinatology, vol. 8, no. 2, pp. 119-127, 1991.

[29] A. Conradt, H. Weidinger, and H. Algayer, "Magnesium therapy decreased the rate of intrauterine fetal retardation, premature rupture of membranes and premature delivery in risk pregnancies treated with betamimetics," Magnesium, vol. 4, no. 1, pp. 20-28, 1985.

[30] M. Makrides and C. A. Crowther, "Magnesium supplementation in pregnancy," Cochrane Database of Systematic Reviews, no. 4, Article ID CD000937, 2002.

[31] W. Doyle, M. A. Crawford, A. H. Wynn, and S. W. Wynn, "Maternal magnesium intake and pregnancy outcome," Magnesium Research, vol. 2, no. 3, pp. 205-210, 1989.

[32] M. Rudnicki, A. Frolich, W. F. Rasmussen, and P. McNair, "The effect of magnesium on maternal blood pressure in pregnancy-induced hypertension. A randomized doubleblind placebo-controlled trial," Acta Obstetricia et Gynecologica Scandinavica, vol. 70, no. 6, pp. 445-450, 1991.

[33] J. Takaya, H. Higashino, F. Kotera, and Y. Kobayashi, "Intracellular magnesium of platelets in children with diabetes and obesity," Metabolism, vol. 52, no. 4, pp. 468-471, 2003.

[34] J. Takaya, F. Yamato, H. Higashino, and Y. Kobayashi, "Relationship of intracellular magnesium of cord blood platelets to birth weight," Metabolism, vol. 53, no. 12, pp. 1544-1547, 2004.

[35] J. Takaya, F. Yamato, H. Higashino, and K. Kaneko, "Intracellular magnesium and adipokines in umbilical cord plasma and infant birth size," Pediatric Research, vol. 62, no. 6, pp. 700$703,2007$.

[36] M. Barbagallo, L. J. Dominguez, and L. M. Resnick, "Magnesium metabolism in hypertension and type 2 diabetes mellitus," American Journal of Therapeutics, vol. 14, no. 4, pp. 375-385, 2007.

[37] L. Venu, Y. D. Kishore, and M. Raghunath, "Maternal and perinatal magnesium restriction predisposes rat pups to insulin resistance and glucose intolerance," Journal of Nutrition, vol. 135, no. 6, pp. 1353-1358, 2005.

[38] J. M. Swanson, S. Entringer, C. Buss, and P. D. Wadhwa, "Developmental origins of health and disease: environmental exposures," Seminars in Reproductive Medicine, vol. 27, no. 5, pp. 391-402, 2009.

[39] I. D. Phillips, G. Simonetta, J. A. Owens, J. S. Robinson, I. J. Clarke, and I. C. McMillen, "Placental restriction alters the functional development of the pituitary-adrenal axis in the sheep fetus during late gestation," Pediatric Research, vol. 40, no. 6, pp. 861-866, 1996. 
[40] S. E. Ozanne, C. L. Wang, N. Colemen, and G. D. Smith, "Altered muscle insulin sensitinity in the male off spring of protein-malnourished rat dams," American Journal of Physiology, vol. 271, no. 6, pp. E1128-E1134, 1996.

[41] R. I. G. Holt, "Fetal programming of the growth hormoneinsulin-like growth factor axis," Trends in Endocrinology and Metabolism, vol. 13, no. 9, pp. 392-397, 2002.

[42] G. C. Burdge, M. A. Hanson, JO. L. Slater-Jefferies, and K. A. Lillycrop, "Epigenetic regulation of transcription: a mechanism for inducing variations in phenotype (fetal programming) by differences in nutrition during early life?" British Journal of Nutrition, vol. 97, no. 6, pp. 1036-1046, 2007.

[43] L. Venu, I. J. N. Padmavathi, Y. D. Kishore et al., "Long-term effects of maternal magnesium restriction on adiposity and insulin resistance in rat pups," Obesity, vol. 16, no. 6, pp. 12701276, 2008.

[44] M. G. Ross and M. Desai, "Gestational programming: population survival effects of drought and famine during pregnancy," American Journal of Physiology, vol. 288, no. 1, pp. R25-R33, 2005. 


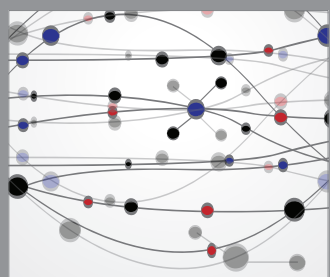

The Scientific World Journal
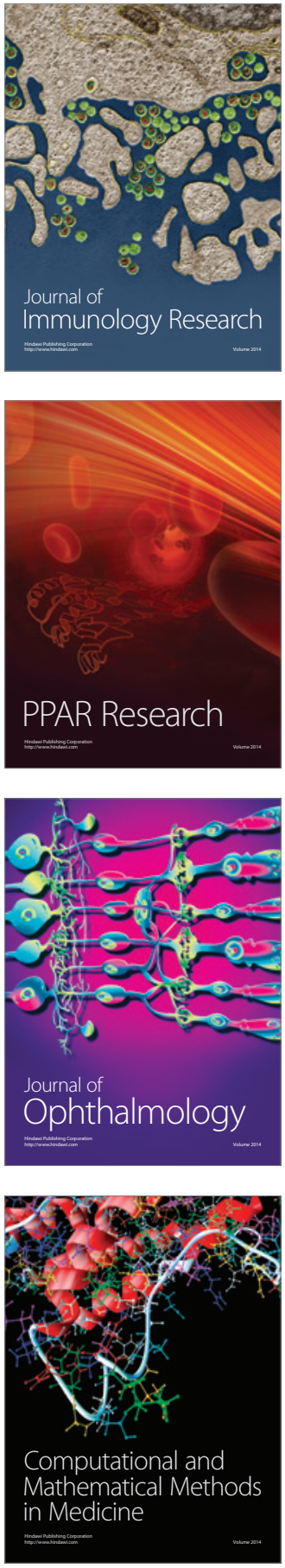

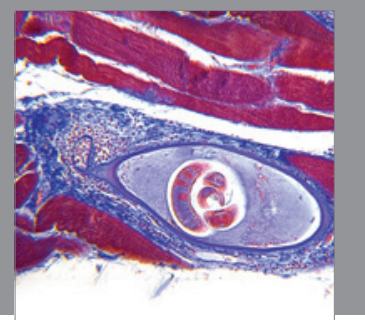

Gastroenterology

Research and Practice
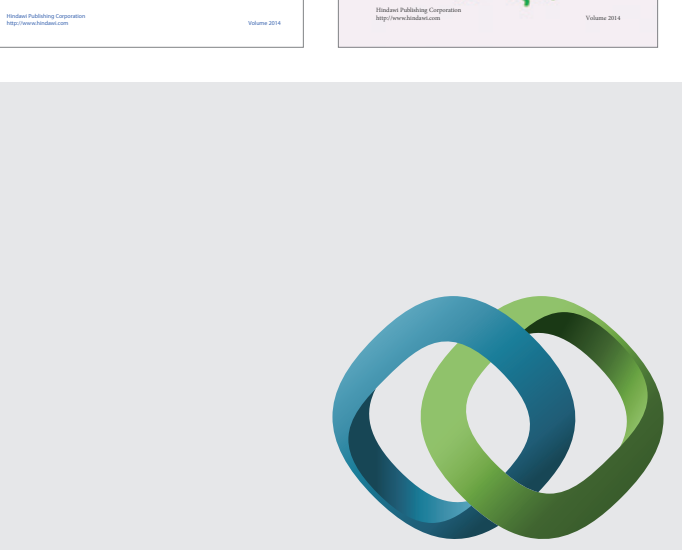

\section{Hindawi}

Submit your manuscripts at

http://www.hindawi.com
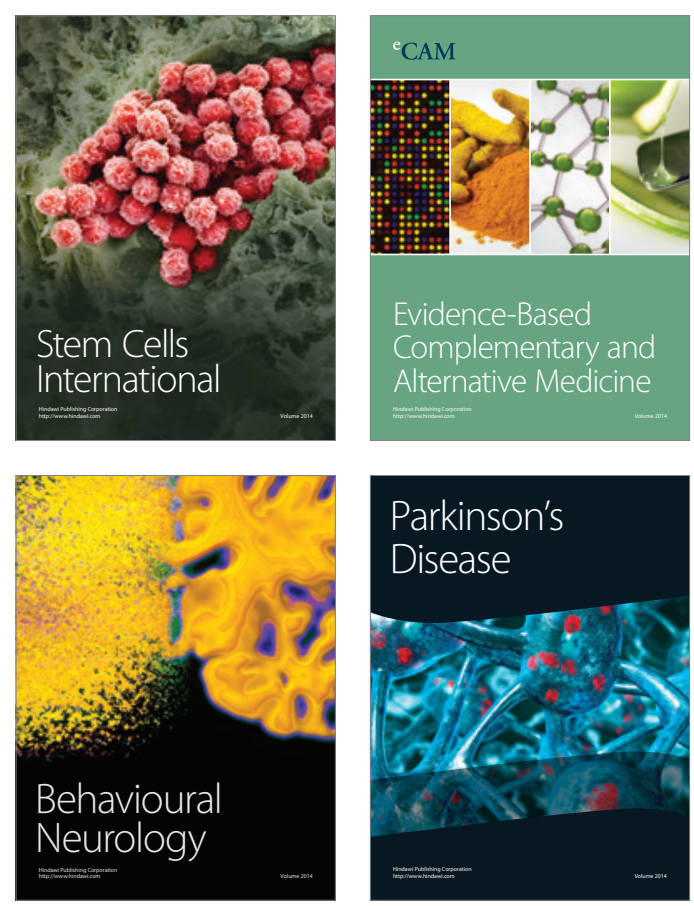

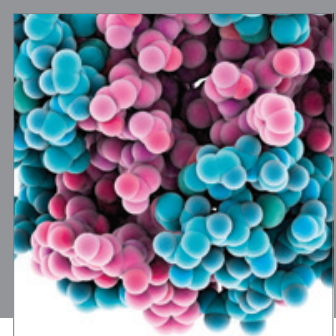

Journal of
Diabetes Research

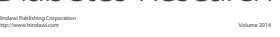

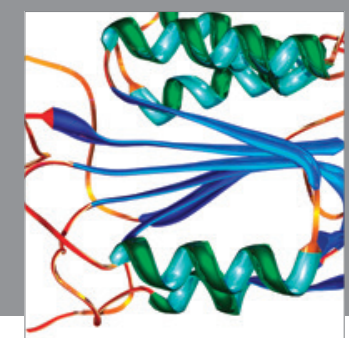

Disease Markers
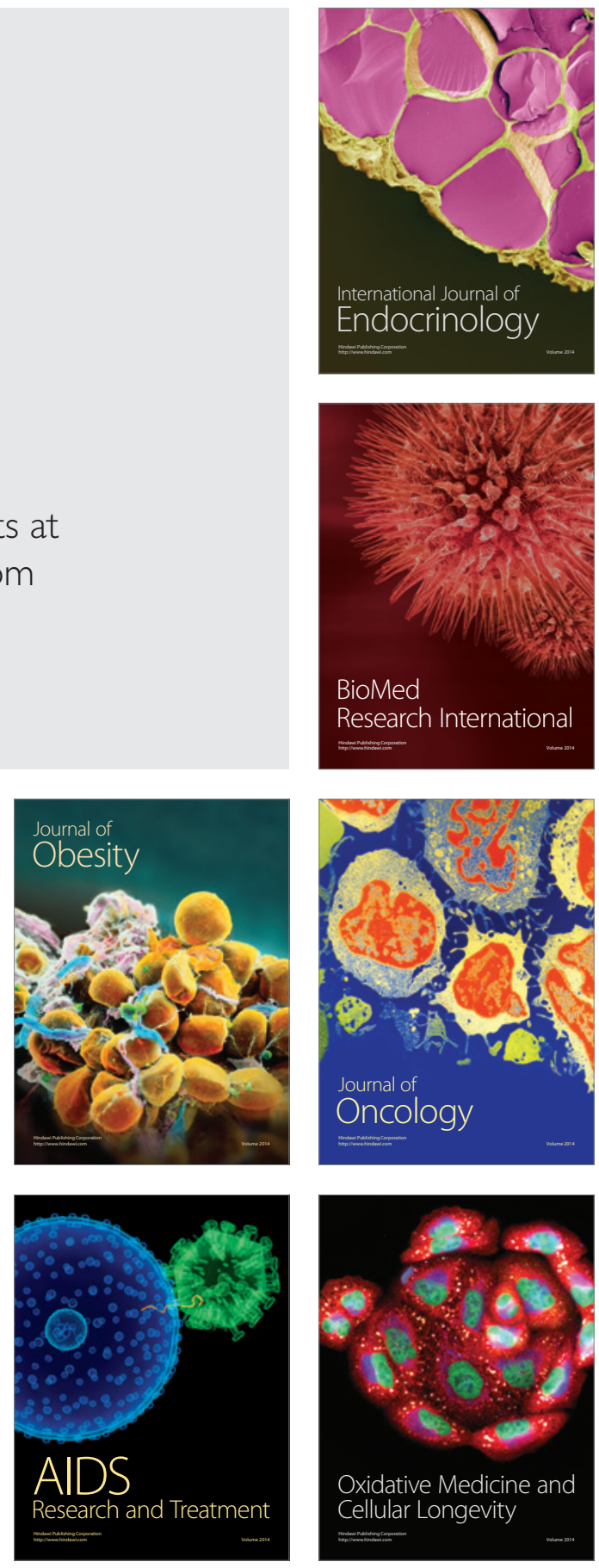